\title{
Physical Activity and BMI in Children of School Age
}

\author{
Anesti Qeleshi, Edison Ikonomi*, Kujtim Kapedani \\ Department of Sport, Faculty of Movement Sciences, Sports University Tirana, Albania
}

DOI: $\underline{10.36348 / \text { jaspe.2019.v02i09.001 }}$

| Received: 06.11.2019 | Accepted: 12.11.2019 | Published: 19.11.2019

*Corresponding author: Edison Ikonomi

Abstract

Physical activity provides important physical, mental and social benefits. In children and adolescents, participation in physical activity is associated with improved musculoskeletal, cardiovascular, and mental health systems, including reducing anxiety and depression. The study aims to support the development of health promotion in school-age children. During March-April 2019 in three cities in Albania we conducted a transversal study with children aged 11 and 13 years. The total number of participants in the study was 1804, out of which 39 were excluded because they were unreliable and 87 were inaccurate in formulation. The participation rate in the study was $1678 / 1804=93 \%$. Anthropometric measurements of children were performed via removable scale and stadiometer. Measuring weight was carried by the weighing scale accuracy \pm 100 gr. and measuring capacity $200 \mathrm{~kg}$ and measuring the length of stadiometer removable scale accuracy of $\pm 1 \mathrm{~mm}$. and the measurement interval from 20-205 cm. It measured 1660/1804=92\% of the children participating. All data analysis was performed using SPSS (Statistical Package for Social Sciences) version 22.0. Reported 87 children $(5.2 \%)$ that were not developed in any physical activity 7 days a week, $415(24.7 \%)$ stated that they had developed physical activity 1-2 days, while 1176 (70.1\%) children reported that they had developed physical activity at least three days of the week. In terms of body mass index categories, $137(8.3 \%)$ of the children were underweight, $1209(72.8 \%)$ had a normal body weight, $236(14.2 \%)$ were overweight, and $78(4.7 \%)$ of the children were obese. Our study found that boys perform more physical activity than girls, and the level of physical activity decreases with age. Attempts to lose weight or to keep the diet resulted more evident in girls than in boys. This behavior was more pronounced with increasing age.

Keywords: children, physical, social, emotional wellbeing, democratic, physical activity, body image, sedentary life.

Copyright @ 2019: This is an open-access article distributed under the terms of the Creative Commons Attribution license which permits unrestricted use, distribution, and reproduction in any medium for non-commercial use (NonCommercial, or CC-BY-NC) provided the original author and source are credited.

\section{INTRODUCTION}

Children's health should be seen as a whole including the physical, social and emotional wellbeing. It is important that health is regarded as an indispensable factor for the activity in everyday life and not as the absence of diseases and physical injuries in the body World Health Organization [1]. In this sense we should be aware that the lifestyle is a social and individual opportunity, conditional and unconditional, useful and harmful, especially when it does not take into account the risk of certain behaviors. Thus, the lifestyle is conditioned by the level and social standard of a particular society, as well as the level of individual development and knowledge of each individual. In this sense takes an important first need to create awareness, education, practicing a style of life as healthy for kids. By this we mean daily life practices for every individual, based on a model for this age regarding active life, nutrition, physical activity, stress management, etc. This need becomes even more necessary if we take into account a population group as minimizing the health statistics of children of school age, which in many cases are combined with youth statistics Currie et al. [2].

Even less attention is paid to inequalities related to socioeconomic status, age, and gender among the age group of school-age children. Therefore, identifying these inequalities and the need for preventive action to turn this vulnerable age into an age of opportunity UNICEF [3].

Adolescence is a critical age for determining the behavior of adults with regard to issues such as the use of tobacco and alcohol, the way of nutrition and physical activity. Health inequalities in adulthood are partly determined by social circumstances at an early age Graham and Power [4]. 
Physical activity provides important benefits physical, mental and social. In children and adolescents, participation in physical activity is associated with improved musculoskeletal, cardiovascular, and mental health systems, including reduction of anxiety and depression Strong et al. [5].

Adolescent participation in physical activity varies based on variables such as gender, age, and ethnicity Sallis, Prochaska and Taylor [6]. It is now recognized that physical activity decreases with age and that girls typically exhibit lower levels of physical activity than boys Nelson et al. [7]; Inchley, Kirby and Currie [8].

The importance of physical activity in the fight against obesity, as well as the health benefits of moderate physical activity include good humor and self-esteem, better physical appearance and posture, significantly reduced obesity, hypertension, cardiovascular disease, diabetes and osteoporosis, reducing the burden of avoidable diseases, the disability and the mortality they cause. Recent guidelines recommend that all individuals should try to do during the day at least 30 minutes of moderate physical activity such as fast walking, cycling, dancing or swimming Inchley, Kirby and Currie [8].

Sedentary behaviors refer not only absence of physical activity but also to engaging in activities that involve minimal movement and low energy expenditure Reilly et al. [9]; Biddle et al. [10]. Already it is recognized more and more the fact that sedentary behaviors are developed independently of the physical activity levels. Sedentary behaviors, such as long standing in front of the TV and playing computer games, have shown that they do not replace the time spent on physical activity Rey-Lopez, VincenteRodriguez and Moreno [11]. However, sedentary behaviors are associated with increased consumption of high calorie intermediate meals Vereecken et al. [12], sugary drink Kremers, Van der Horst and Brug [13], as well as high levels of obesity Rennie, Johnson and Jebb [14].

Body weight control, diet maintenance and weight control behaviors are common among adolescents. Girls are more likely to lose weight than boys, who are more likely to engage in risky behaviors that control weight Larson, Neumark-Sztainer and Story [15]. Self-perception of being overweight is an important factor that leads to weight loss efforts, thus emphasizing the importance of promoting a healthy body image. In western societies, the desire to have a slim body is especially common, especially in girls. This phenomenon causes many normal weight girls to perceive themselves overweight Ojala et al. [16].

Teenagers concerns about their body image are influenced by the media and peers, resulting in increased pressure for girls to be thin and boys with muscles McCabe, Ricciardelli and Finemore [17]; Wertheim, Paxton, Schutz and Muir [18]. Therefore girls tend to maintain a diet, while boys are more likely to train to achieve their desired body shape and size Ricciardelli, McCabe and Banfield [19].

On the other hand, dissatisfaction with body image is associated with some risky weight control behaviors, such as consuming large amounts of food in boys Lynch, Heil, Wagner and Havens [20]; NeumarkSztainer, Paxton, Hannan, Haines and Story [21]. Weight loss behaviors in non-overweight children are also associated with significant risk to physical health and emotional wellbeing. For this reason, promoting safe and sensible approaches to weight management is very important for the wellbeing of young people Kelly, Molcho and Nic Gabhainn [22].

Body image involves youth self-perception of their body and plays an important role in the development of self-esteem Davison and McCabe [23], as it influences behaviors related to eating habits and physical activity Huang et al. [24].

High levels of dissatisfaction with body image are predictors of a negative perception of health Meland, Haughland and Breidablik [25], eating disorders Espinoza, Penelo and Raich [26] and depressive conditions Stice et al. [27]. On the other hand, the influence of the media increases the importance of physical appearance Thompson and Stice [28].

However, increased communication with parents contributes to the reduction of dissatisfaction with body image Al Sabbah et al. [29]. Body mass index (BMI) is calculated using weight and length sizes. For its calculation, in childish age growth curves used by WHO.

The epidemic of obesity is a worldwide phenomenon, which obliges policymakers to decide this issue in their political agenda. Thus, prevention of overweight and obesity is addressed in the plan for food and nutrition, where for achieving this objective under the optics of an integrated approach to reduce risk factors associated with chronic diseases, which is part of the obesity.

Perceived weight does not always reflect the current state of weight based on BMI. It is more common in adolescents to underestimate body weight than to overestimate it. The prevalence of underestimation of body weight is greater among boys and ethnic minorities. Between BMI and body image dissatisfaction was found a positive relationship Presnell, Bearman and Stice [30]. Thus, dissatisfaction with body image is higher and more common in girls than boys, among overweight adolescents than in 
normal weight adolescents and among those who are older in age Currie et al. [31]; Al Sabbah et al. [29].

\section{PURPOSE AND OBJECTIVES OF THE STUDY \\ Among these goals we can mention}

- Make the connection that children's behaviors are related to health.

- To support the development of health promotion in school-age children.

- To assess behaviors related to health, eating habits, physical activity and energy spent.

- Describe the health status of children; positive health, weight and body image.

- To disseminate the findings of the study to teachers, parents and children's.

- Increase understanding of adolescent healthy behaviors and lifestyles in their social context.

\section{METHODOLOGY}

During March-April 2019, in three cities of Albania we conducted a transversal study with 1804 children aged 11 and 13 years. Age groups of children were sampled by time periods representing the onset of adolescence. Age 11 years begins the challenge of physical changes and emotional. Age 13 years is the years when they start to take very important decisions about life and career.

\section{Sample size}

Based on international protocols, according to the HBSC, the sample number for each age group is 1550 children (based on analyzes of studies carried out in 1993-94 and 1997-98, this calculation provides a confidence interval (CI) of $+/-3 \%$ to $95 \%$ and a design effect of 1.2). To increase the power of the study and calculate the rate of refusal to participate in the study, a sample of 1804 individuals was calculated. The technique used for sample selection was cluster sampling, where the cluster was the class of a school. Classes were chosen at random. For the sample selection, age was the first priority. The stratification was based on three cities of Albania, Tirana, Elbasan and Berat. The study was conducted at the end of the academic year 2018-2019 and the children of a certain age group were likely to be found in two different levels of classes. For example, children belonging to the age group of 11 years were in the fifth class, but also in the sixth class. Children belonging to the 13 year old age group were in the seventh class, but also in the eighth class. As a result, the target population of the study (ages 11 and 13) was distributed across the 4 classes levels, specifically from the 5th class (11 years old) in 8th class (13 years old), including only 9 years schools in the study. After a preliminary estimate, it was decided that it should be the same distribution of the same age group children from each classes level $(50 \%$ of children from fifth class and $50 \%$ of sixth class) forming the equivalent classes.

The total number of participants in the study was 1804 , of which the realization of the questionnaire 39 were excluded because they were not reliable and the 87 questionnaires as incorrect in formulation.

The participation rate in the study was $1678 / 1804=93 \%$ and the distribution of participants is presented in Table- 1 .

Table-1: Number of children by city, classes, school

\begin{tabular}{|c|c|c|c|c|}
\hline $\mathbf{N}^{\mathbf{0}}$ & City & $\mathbf{N}^{\mathbf{0}}$ total of schools & $\mathbf{N}^{\mathbf{0}}$ total of classes & $\mathbf{N}^{\mathbf{0}}$ total of children \\
\hline 1 & Berat & 4 & 14 & 196 \\
\hline 2 & Elbasan & 7 & 21 & 325 \\
\hline 3 & Tirana & 19 & 72 & 1283 \\
\hline $\mathbf{4}$ & Total & $\mathbf{3 0}$ & $\mathbf{1 0 7}$ & $\mathbf{1 8 0 4}$ \\
\hline
\end{tabular}

Data collection consisted of self-administered standard questionnaire, which consisted of 11 compulsory questions. The questionnaire contained the following items: behaviors related to physical activity, weight control, sedentary behaviors, health, assessment of physical development, body image, diet. Confidentiality was extremely important as a procedure to ensure children anonymity through the data collection process. The interviewers were the physical education teachers of the schools in the study, where in addition to the instructions written at the top of the questionnaire, children were given verbal instructions on how to complete the questionnaire anonymously. Only children's who completed the questionnaire were included in the study.
The study included all sampled children who were present on the day of anthropometric measurements, regardless of their age. It was envisaged that children who would not allow their parents to participate in the measure would not be included. However, there was no rejection by parents regarding the participation of their children in this study, as well as by children during the process of anthropometric measurements in classrooms. No request was denied by school staff regarding anthropometric measurements of children. Anthropometric measurements of children were performed via removable scales and stadiometers. Weight measurement was performed using scales, with an accuracy rate of \pm 100 gr and measurement capacities of $200 \mathrm{~kg}$, as well as length measurement with removable stadiometers with an accuracy of \pm 1 
$\mathrm{mm}$ and a measurement range of 20-205 cm. 1660/ $1804=92 \%$ of participating children were measured.

\section{Steps to perform fieldwork First step}

It started in February 2019, where a week before the start of the study, was the announcement of the schools that will participate in the study. At the same time, schools were required to notify parents whose children would participate in the study in order to obtain their approval.

\section{Second step}

It was interviewer training and piloting the questionnaire. Before the fieldwork began, the working group organized a two-day training session with all interviewers who were physical education teachers of the schools under study. Participants received detailed instructions, instructions on how to maintain confidentiality and how to avoid influenced responses. During the second day of training interviewers, took field piloting the questionnaire. It was conducted in the presence of the entire study working group and for each age group. This process was conducted in two Tirana schools and the number of children involved was 50 .

\section{Last step}

During March - April 2019, all the questionnaires were distributed according to the selected schools, as well as the anthropometric measurements of the children participating in the study. All the children were informed about the purpose and objectives of the study and explained in sufficient detail especially the data related to the questionnaire.

\section{DATA ANALYSIS}

Data analysis identified significant differences in the prevalence of health consequences, matched by gender and age group. The Hi-square test was used to assess statistically significant statistical differences related to gender and age group. Only statistically significant results are included in the report. A 95\% significance level was used in the comparison of the proportions. All data analysis was performed through SPSS (Statistical Package for Social Sciences, version 22.0). Interpretation of all study results was done very carefully also by the type of study. Since, it was a transversal (cross-sectional) study.

\section{RESULTS AND DISCUSSIONS Physical activity and sedentary life}

- $70.1 \%$ of children 11-13 years old are involved in physical activity during the 3 days of the week.

- Boys (76\%) perform more physical activity 3 times a week than girls $(65 \%)$.

- Three in four children ages 11-13 spend two or more hours a week watching television or video.

- Boys play computer games than girls, both during the weekend as well as weekdays.

\section{Physical activity}

Participation in physical activity was assessed by asking. During the 7 days of the week, how many of you were physically active for at least 60 minutes in day? The number of days was categorized into 3 variables: 0 days, 1-2 days, and> 3 days. 87 children $(5.2 \%)$ reported not having physical activity on any of the 7 days of the week, $415(24.7 \%)$ reported having developed physical activity for 1-2 days, while 1176 $(70.1 \%)$ children reported having developed physical activity at least three days of the week. There is a significant gender difference between boys and girls performing physical activity over 3 days a week, $76 \%$ boys versus $65 \%$ girls Figure- 1 .

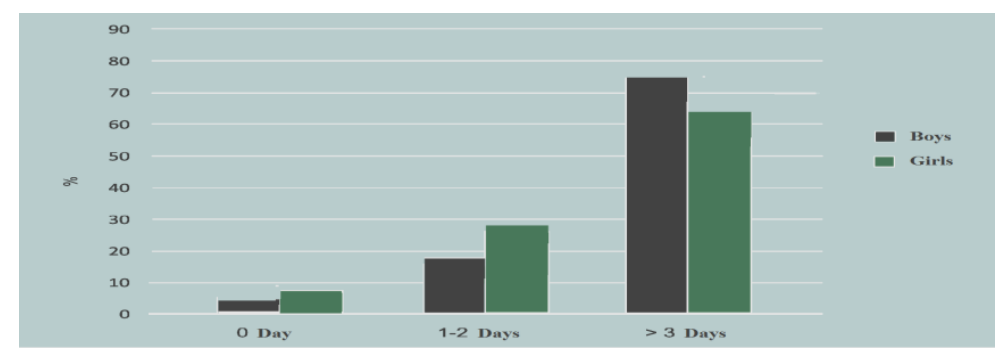

Fig-1: Performing physical activity over three days a week by gender

\section{Sedentary life}

The children's were asked. How many hours per day of leisure time spent watching television, videos (including YouTube or similar services), DVDs and other entertainment on the screen? How many hours spent playing computer games? How many hours they spent using a computer or smart phone? Their responses found that for all three questions, there were more youth spending two or more hours at the weekend compared to weekdays Figure-2. The most pronounced activity was watching television, videos or other on-screen entertainment $(75.8 \%)$. There was generally no age difference with regard to hours spent in leisure time, but boys were more likely to stay longer than girls performing these activities. 


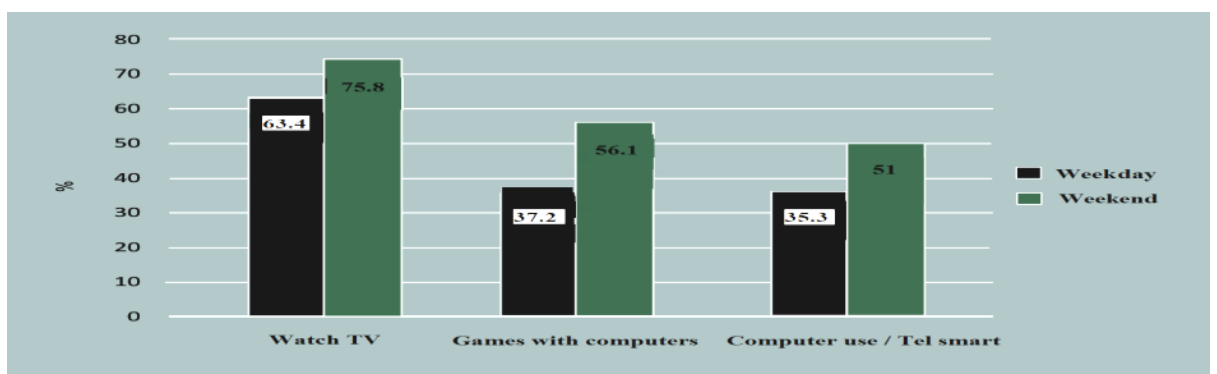

Fig-2: Spending free time during the week

\section{Behaviors that control body weight, body image and} body mass index

- $7.3 \%$ of children aged $11-13$ are on a diet to lose weight.

- The proportion of girls who have a negative selfperception of their weight and / or maintain the diet is higher than men $(8.5 \%$ versus $6.1 \%)$.

- $64.8 \%$ of $11-13$ years children who attend the school are of normal weight versus $4.7 \%$ classified as obese.

- Compared to boys, girls are more underweight (9.2\% versus $7.4 \%)$.

- Children 11 years old were more underweight, overweight and obese compared with those 13 years of age.
- Girls tend to report normal weight compared to boys.

\section{Behaviors that control body weight}

To assess behaviors that control body weight, children's were asked if they were on a diet or doing anything else to lose weight.

In total, $7.3 \%$ of children are reported being on a diet. Of these, girls were more likely to diet were compared with boys $(8.5 \%$ versus $6.1 \%)$, or thought they should begin to bear diet to lose weight $(16.3 \%$ versus $10.4 \%$ ). Need to maintain a diet increased with the age of children's Figure-3.

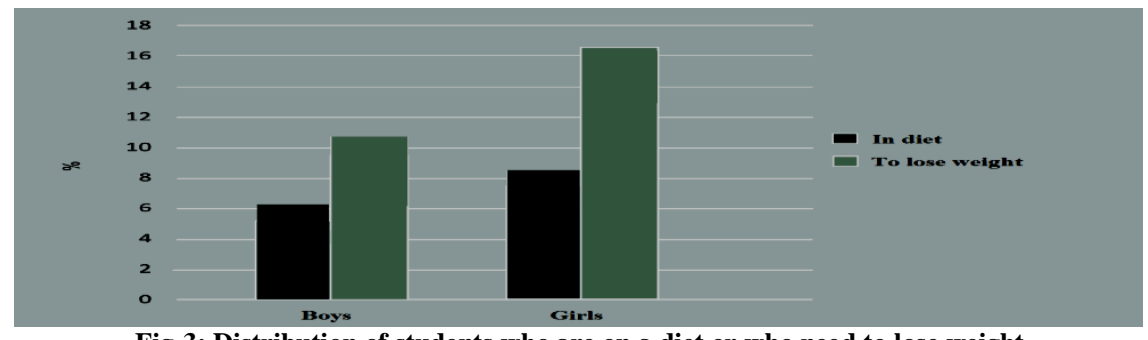

Fig-3: Distribution of students who are on a diet or who need to lose weight

\section{Body image}

Regarding self-perception of body image, $3.4 \%$ of children's think that their body is very healthy and $2.7 \%$ think that their body is very weak. However, there is evidence of a statistically significant difference in the level of bad perception of body image between boys and girls. Thus, the proportion of girls who have a negative self-perception of their weight and / or diet is higher compared to boys.

\section{Body mass index}

Assessment of children's body mass was based on the measurement of weight (in $\mathrm{kg}$ ), length (in meters) using four categories: underweight, normal weight, overweight and obese. It should be noted that obesity values that vary from measurements tend to be lower than those obtained from health examinations Elgar et al. [32].

Regarding the categories of body mass index according to the World Health Organization (WHO) classification, 137 (8.3\%) children's were underweight, $1209(72.8 \%)$ had normal body weight, $236(14.2 \%)$ were overweight, while $78(4.7 \%)$ of the children's were obese. Overweight, underweight, and obesity were more frequently reported by 11 years compared to 13 years. Girls are also more likely to report normal weight than boys. A higher percentage of girls (9.2\%) than boys $(7.4 \%)$ were classified as overweight and a higher percentage of boys ( $18.1 \%$ compared to $10.3 \%$ among girls) were classified as overweight Figure-4. 


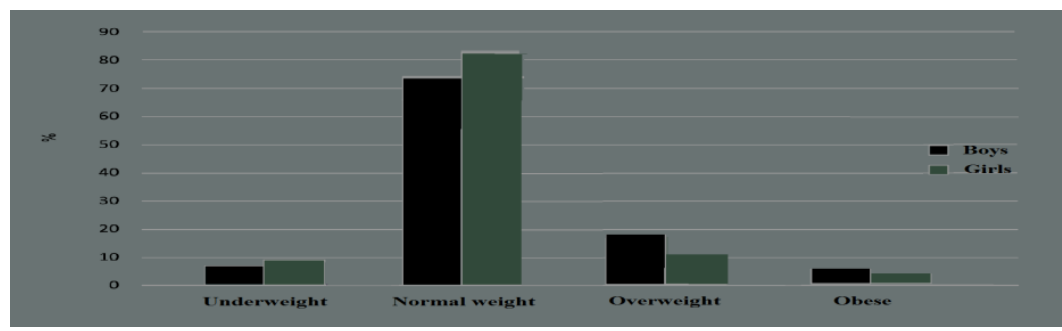

Fig-4: Prevalence of body mass reported by age group

\section{CONCLUSIONS}

\section{Physical activity and sedentary life}

Performing physical activity is considered a protective factor for maintaining optimal body weight as well as against cardiovascular disease. As in many previous studies, our study also found that boys perform more physical activity than girls, and the level of physical activity decreases with age. On the other hand, watching television was the most sedentary activity among children aged 11-13 years. These findings emphasize the need for interventions aimed at increasing physical activity, especially in older children and girls. Such interventions may be:

- Providing a range of activities that attract especially girls.

- Providing of suitable sports facilities for children Biddle et al. [33].

- Educating the public through media campaigns, emphasizing the need for physical activity.

- Development of school programs that promote classes with high sports activity.

- Parental involvement in supporting and encouraging children to perform physical activity Brunton et al. [34].

- Monitoring the use of television and video Brunton et al. [34].

\section{Body weight}

Attempts to lose weight or to keep the diet resulted in more evident in girls than boys. This behavior was more pronounced with increasing age. Gender differences may be partially explained by changes during puberty, a period in which girls, increased weight see as a barrier to keep the ideal body shape Hargreaves and Tiggemann [35].

Boys tend to be more overweight than girls. The reasons for this result may be related to the fact that girls eat healthier, boys eat more fast-food and parents encourage less boys to control their weight. Sweeting [36].

\section{Body image}

Regarding body image from our study showed that girls are less likely to report that they are very healthy compared to boys. This result is similar to the Eastern European countries, while the opposite is true for girls from Western and Central Europe Currie et al. [2].
Given that, the problems associated with weight are related to gender, it is necessary to design gender-specific strategies, as bodily image and the problems associated with weight are strongly dependent on different pubertal development between girls and boys, as well as from different socio-cultural expectations. Richardson, Paxton and Thomson [37].

Necessary preventive components should include nutrition, promoting an active life, reducing stigma over weight and body shape, media information and effective stress management Haines and NeumarkSztainer [38].

\section{ACKNOWLEDGMENTS}

The authors wish to thank all: children's, school directors, school staff (teachers), parents, who helped and participated in the present study.

\section{REFERENCES}

1. World Health Organization. (2016). Constitution WHO Geneva.

2. Currie, C. (2013). Social determinants of health and well-being among young people. Health behaviour in school-aged children (HBSC) study. International report from the 2009/ 2010 survey.

3. UNICEF. (2011). The state of the world children. Adolescence an age of opportunity. New York.

4. Graham, H., \& Power, C. (2004). Childhood disadvantage and adult health: a life course framework. London Health Development Agency.

5. Strong, W.B., Malina, R.M., Blimkie, C.J.R., Daniels, S.R., Dishman, R.K., Gutin, B., Hergenroeder, A.C., Must, A., Nixon, P.A., Pivarnik, J.M., Rowland, T., Trost, S. \& Trudeau, F. (2005). Evidence based physical activity for school-age youth. Journal of Pediatrics, 146(2), 732-737.

6. Sallis, J.F., Prochaska, J.J. \& Taylor, W.C. (2000). A review of correlates of physical activity of children and adolescents. Medicine \& Science in Sports \& Exercise, 32(5), 963-975.

7. Nelson, M.C., Neumark-Stzainer, D., Hannan, P.J. \& Sirard, J.R. (2006). Longitudinal and secular trends in physical activity and sedentary behavior during adolescence. Pediatrics, 118: 1627-1634.

8. Inchley, J., Kirby, J., \& Currie, C. (2008). Physical activity among adolescents in Scotland: final report of the Physical Activity in Scottish Schoolchildren (PASS) study. Edinburgh: Child and Adolescent 
Health Research Unit. The University of Edinburgh.

9. Reilly, J.J., Coyle, J., Kelly, L.A., Burke, G.,Grant, S. \& Paton, J.Y. (2003). An objective method for measurement of sedentary behavior in 34 year olds. Obesity Research, 11(6), 1155- 1158.

10. Biddle, S.J., Gorely, T., Marshall, S.J., Murdey, I. \& Cameron, N. (2004). Physical activity and sedentary behaviours in youth issues and controversies. Journal of the Royal Society for the Promotion of Health. 124(6), 29-33.

11. Rey-Lopez, J.P., Vincente-Rodriguez, G., Biosca, M. \& Moreno, L.A. (2008). Sedentary behaviour and obesity development in children and adolescents. Nutrition, Metabolism and Cardiovascular Diseases, 18(4), 242-251.

12. Vereecken, C.A., Todd, J., Roberts, C., Mulvihill, C. and Maes, L. (2006). Television viewing behaviour and associations with food habits in different countries.

13. Kremers, S.P.J., Van der Horst, K. \& Brug, J. (2007). Adolescent screen-viewing behaviour is associated with consumption of sugar-sweetened beverages. The role of habit strength and perceived parental norms. Appetite, 48(1), 345-350.

14. Rennie, K.L., Johnson, L., \& Jebb, S.A. (2005). Behavioural determinants of obesity. Best Practice \& Research Clinical Endocrinology \& Metabolism, 19(3), 343-358.

15. Larson, N. I., Neumark-Sztainer, D., \& Story, M. (2009). Weight control behaviors and dietary intake among adolescents and young adults: longitudinal findings from Project EAT. Journal of the American Dietetic Association, 109(11), 18691877.

16. Ojala, K., Vereecken, C., Välimaa, R., Currie, C., Villberg, J., Tynjälä, J., \& Kannas, L. (2007). Attempts to lose weight among overweight and non-overweight adolescents: a cross-national survey. International Journal of Behavioral Nutrition and Physical Activity, 4(1), 50.

17. McCabe, M.P., Ricciardelli, L.A., \& Finemore, J. (2002). The role of puberty, media and popularity with peers on strategies to increase weight, decrease weight and increase muscle tone among adolescent boys and girls. Journal of Psychosomatic Research, 52(3), 145-153.

18. Wertheim, E. H., Paxton, S. J., Schutz, H. K., \& Muir, S. L. (1997). Why do adolescent girls watch their weight? An interview study examining sociocultural pressures to be thin. Journal of psychosomatic research, 42(4), 345-355.

19. Ricciardelli, L.A., McCabe, M.P., \& Banfield, S. (2000). Body image and body change methods in adolescent boys. Role of parents, friends and the media. Journal of Psychosomatic Research, 49(4), 189-197.

20. Lynch, W.C., Heil, D.P., Wagner, E., \& Havens, M.D. (2008). Body dissatisfaction mediates the association between body mass index and risky weight control behaviors among White and Native American adolescent girls. Appetite, 51(3), 210213.

21. Neumark-Sztainer D., Paxton S.J., Hannan P.J., Haines, J., \& Story, M. (2006). Does body satisfaction matter? Five-year longitudinal associations between body satisfaction and health behaviors in adolescent females and males. Journal of Adolescent Health, 39 (7), 244251.

22. Kelly,C., Molcho, M., \& NicGabhainn, S. (2009). Patterns in weight reduction behaviour by weight status in schoolchildren. Public Health Nutrition, 13(8), 1229-1236.

23. Davison, T.E., \& McCabe, M.P. (2006). Adolescent body image and psychosocial functioning. The Journal of Social Psychology, 146(4), 15-30.

24. Huang, J.S., Norman, G.J., Zabinski, M.F., Calfas, K., \& Patrick, K. (2007). Body image and selfesteem among adolescents undergoing an intervention targeting dietary and physical activity behaviors. Journal of Adolescent Health, 40(2), 245-251.

25. Meland, E., Haugland, S., \& Breidablik, H. J. (2006). Body image and perceived health in adolescence. Health Education Research,22(3), 342-350.

26. Espinoza, P., Penelo, E., \& Raich, R. M. (2010). Disordered eating behaviors and body image in a longitudinal pilot study of adolescent girls: What happens 2 years later?. Body image, 7(1), 70-73.

27. Stice, E., Hayward, C., Cameron, R.P., Killen, J. D., \& Taylor, C. B. (2000). Body-image and eating disturbances predict onset of depression among female adolescents. Journal of Abnormal Psychology, 109(3), 438-444.

28. Thompson, J. K., \& Stice, E. (2001). Thin-ideal internalization: Mounting evidence for a new risk factor for body-image disturbance and eating pathology. Current directions in psychological science, 10(5), 181-183.

29. Al Sabbah, H., Vereecken, C. A., Elgar, F. J., Nansel, T., Aasvee, K., Abdeen, Z., ... \& Maes, L. (2009). Body weight dissatisfaction and communication with parents among adolescents in 24 countries: international cross-sectional survey. BMC public health, 9(1), 52.

30. Presnell, K., Bearman, S.K., \& Stice, E. (2004). Risk factors for body dissatisfaction in adolescent boys and girls: A prospective study. International Journal of Eating Disorders, 36(4), 389-401.

31. Currie, C., Molcho, M., Boyce, W., Holstein, B., Torsheim, T., \& Richter, M. (2008). Researching health inequalities in adolescents: the development of the Health Behaviour in School-Aged Children (HBSC) family affluence scale. Social science \& medicine, 66(6), 1429-1436.

32. Elgar, F.J., Roberts, C., Tudor-Smith, C., \& Moore, L. (2005). Validity of self-reported height and 
weight and predictors of bias in adolescents. Journal of Adolescent Health, 37(5): 371-375.

33. Biddle, S. J., Gorely, T., Marshall, S. J., Murdey, I., \& Cameron, N. (2004). Physical activity and sedentary behaviours in youth: issues and controversies. The journal of the Royal Society for the Promotion of Health, 124(1), 29-33.

34. Brunton, G., Harden, A., Rees, R., Kavanagh, J., Oliver, S., \& Oakley, A. (2003). Children and physical activity: a systematic review of barriers and facilitators. In Database of Abstracts of Reviews of Effects (DARE): Quality-assessed Reviews [Internet]. Centre for Reviews and Dissemination (UK).
35. Hargreaves DA, Tiggemann M. 'Body Image is for Girls' A Qualitative Study of Boys' Body Image. Journal of health psychology. 2006 Jul;11(4):56776.

36. Sweeting, H. N. (2008). Gendered dimensions of obesity in childhood and adolescence. Nutrition journal, 7(1), 1. Richardson, S. M., Paxton, S. J., \& Thomson, J. S. (2009). Is BodyThink an efficacious body image and self-esteem program? A controlled evaluation with adolescents. Body Image, 6(2), 7582.

37. Haines, J., \& Neumark-Sztainer, D. (2006). Prevention of obesity and eating disorders: a consideration of shared risk factors. Health education research, 21(6), 770-782. 